\title{
SISTEMAS DE GÊNEROS E RECONTEXTUALIZAÇÃO DA CIÊNCIA NA MÍDIA ELETRÔNICA ${ }^{1}$
}

Désirée Motta-Roth

Recebido 12, abr. 2010 / Aprovado 17, mai. 2010

\section{Resumo:}

Neste trabalho, exploro o processo de popularização da ciência a partir de dois conceitos: sistema de gêneros e recontextualização. Combino as concepções sociorretórica e sistêmico-funcional de gênero discursivo com a perspectiva sóciohistórica (conforme creditada a Mikhail Bakhtin e a outros autores na mesma linha) para definir gênero como um evento discursivo recorrente em esferas específicas de atividade humana. Enfoco o processo discursivo implementado pela midiatização de pesquisas científicas em publicações de popularização da ciência divulgadas na internet. A transposição de um conteúdo ideacional da ciência (a nova pesquisa, sua metodologia e seus resultados) para a mídia eletrônica se dá por um movimento de recontextualização que realoca (partes ou todo de) textos de uma esfera de atividade humana para outra, dando visibilidade a um fluxo contínuo entre gêneros de um mesmo sistema de produção e manutenção da ciência.

1 Este artigo apresenta resultados do Projeto PQ/CNPq "Análise crítica de gêneros com foco em artigos de popularização da ciência", desenvolvido com apoio da BolsaPQ/CNPq ${ }^{\circ}$ 301962/2007-3, e do estágio Pósdoutoral em Linguística Aplicada, realizado no LAEL-PUCSP, sob supervisão da Profa. Dra. Leila Barbara. Agradeço a Patrícia Marcuzzo (PPGL/UFSM) e Anelise Scherer (PIBIC/UFSM) pela leitura da versão anterior deste texto.
Palavras-chave: Gênero discursivo. Esfera de atividade humana. Sociorretórica. Popularização da ciência 


\section{Introdução}

Em sua raiz latina, a palavra "ciência", scientia, significa "conhecimento" (FERREIRA, 1986) e pode se referir à observação, identificação, descrição e explicação de qualquer objeto ou fenômeno com base em um sistema de ideias vigente. É a busca da humanidade por compreender o universo e seu lugar dentro dele (HORGAN, 1998, p. 15). Em termos práticos, ciência se refere a qualquer questão a ser resolvida, desde que haja tempo e recursos suficientes (IDEM, IBIDEM). Realisticamente, é o apoio das forças econômicas e políticas da sociedade que consagrará qualquer área do conhecimento ou teoria como ciência, garantindo a continuidade ou a mudança de paradigmas (MOTTA-ROTH, no prelo, p.1).

A "visão canônica" de ciência e de sua popularização pressupõe dois discursos separados: um discurso de autoridade, dentro das instituições científicas, e um discurso público externo a elas (MYERS, 2003, p.266). Tal divisão só interessaria às próprias instituições científicas como meio de manutenção do poder na sociedade. Se ciência é uma ordem do discurso com gêneros, práticas sociais e ideologias articuladas em redes, textos de popularização são parte essencial dessa rede, uma vez que a sobrevivência das áreas de conhecimento depende do apoio da sociedade mais ampla, via financiamento e políticas públicas (MYERS, 1990, p. 145), que só terá acesso à pesquisa recente pela midiatização da ciência.

Neste trabalho, exploro o processo de midiatização ou popularização da ciência (PC) a partir de dois conceitos: sistema de gêneros e recontextualização. Assumo a concepção sociorretórica de gênero discursivo que incorpora a perspectiva sócio-histórica creditada a Mikhail Bakhtin (e outros autores que o atualizam) como um evento discursivo recorrente em esferas de atividade humana. Um evento discursivo é uma atividade dinâmica de uso da linguagem que combina recursos sociais e cognitivos na produção de sentido; é uma ecologia dinâmica e complexa em funcionamento, com pessoas posicionadas em uma rede social, que usam outros sistemas complexos - de linguagem e outros meios semióticos - para interagir umas com as outras (LARSEN-FREEMAN; CAMERON, 2008, p. 161-162; 186).

Enfoco o processo discursivo de midiatização eletrônica de pesquisas científicas em um gênero/evento discursivo na internet: a notícia eletrônica de PC. O conteúdo ideacional da ciência (a nova pesquisa, sua metodologia e resultados) é midiatizado por um movimento de reposicionamento de textos (ideias, discursos, ou qualquer coisa que possa ser semiotizada) de uma esfera de atividade humana para outra. Meu argumento é que, em vez de uma separação entre discursos, o processo de recontextualização dá visibilidade a um fluxo (ora contínuo, ora 
com estreitamentos) entre gêneros que integram um mesmo sistema de criação, recriação e manutenção $0^{1,2}$ da ciência.

Na primeira seção deste artigo, situo a discussão sobre gêneros discursivos e sistemas de gêneros. Na segunda, abordo o processo de recontextualização para explicar a transposição do objeto da ciência (constituído textualmente no contexto primário de produção científica, com seu sistema de atividades, gêneros discursivos e papeis institucionais) para o contexto (secundário) da mídia, também com seus sistemas específicos. Busco demonstrar o modo como jornalistas recontextualizam a ciência por meio de estratégias discursivas de pedagogização e de midiatização, envolvendo dois princípios: dialogismo e intertextualidade.

\section{Gêneros discursivos e sistemas de gêneros}

A última década do século XX e a primeira década do XXI ensejaram a projeção de múltiplos olhares sobre o fenômeno dos gêneros discursivos. Nessa fase, os estudos da linguagem têm dado especial atenção aos processos e às condições de contextualização do discurso. Referências aos escritos creditados ao círculo de Mikhail Bakhtin (1995; 1992), aos estudos da Sociorretórica (BAZERMAN, 2005; SWALES, 1998) e às análises críticas do discurso (CHOULIARAKI; FAIRCLOUGH, 1999) são cada vez mais frequentes. Especialmente nas duas últimas décadas, as discussões sobre os gêneros discursivos voltam a fixar um ponto mais além dos limites do léxico, da gramática e do texto, na direção do contexto social, do discurso e da ideologia (BERKENKOTTER, 2001).

\subsection{Gêneros discursivos}

As condições de produção, distribuição e consumo do texto têm sido focalizadas nos estudos dos gêneros que circulam na sociedade. Olham-se as práticas sociais que estão em relação dialética com os gêneros que as constituem e por elas são constituídos, em uma reciprocidade entre a experiência da vida e o conteúdo, o estilo e a construção composicional dos enunciados.

2 Em um fluxo, como por exemplo, entre produção de um artigo acadêmico (criação) sua recontextualização na notícia (recriação), desenvolvimento de novas pesquisas, impulsionado pelo interesse da sociedade (manutenção), nessa ordem ou em diversas outras ordens possíveis entre essas etapas.
Exemplifico essa perspectiva primeiramente com a texto-
grafia de John Swales (1998) sobre as práticas sociais e discursivas das formas de vida em três comunidades acadêmicas que convivem diariamente em um mesmo edifício no campus da Universidade de Michigan, Estados Unidos: o departamento de Botânica, o Instituto de Língua Inglesa e um centro de computação. Para analisar o papel dos diferentes gêneros em cada comunidade, Swales busca a visão etnográfica, interna à disciplina, conforme dada por seus membros, em vez da interpretação eminentemente externa do analista do discurso. Ao realizar um estudo a que chama de "textográfico", Swales busca fazer sentido 
de cada comunidade de prática por meio da análise do discurso e da episteme locais. Observa o contexto físico, toma notas de campo, entrevista os participantes e analisa os gêneros mobilizados por esses participantes na sua experiência de trabalho diário. Analisa o sistema complexo dos gêneros discursivos que possibilitam a cada comunidade produzir conhecimento no seu campo específico.

O segundo exemplo versa sobre o funcionamento de dois gêneros que atualizam as estruturas sociais da tradição cultural islâmica. Sob a perspectiva da Análise Crítica de Gênero, Al-Ali analisa (respectivamente 2005; 2006) a maneira como o aviso fúnebre e o convite de casamento atualizam e, ao mesmo tempo, são determinados pelas tradições culturais (religiosas, morais, etc.) da sociedade Jordaniana. $\mathrm{O}$ estudo sobre o gênero aviso fúnebre nos remete a dois momentos da tradição contemporânea daquela sociedade: a morte natural e a morte de mártires (seja por acidente ou por sacrifício à jihad - a guerra santa islâmica). Al-Ali (2005) analisa as crenças, normas e práticas socioculturais de seu país no discurso. Se o primeiro tipo de anúncio expressa pesar, o segundo incorpora um discurso promocional do falecido para expressar o orgulho e a honra por parte daquele que anuncia o passamento. $\mathrm{O}$ autor nos faz ver a influência dos fatores socioculturais sobre eventos discursivos.

Nessa perspectiva, o mesmo autor (2006) analisa um corpus de 200 convites de casamento de toda a Jordânia e revela o modo como o poder masculino é exercido em todas as camadas da tessitura textual do gênero. $\mathrm{O}$ enunciado simples e curto do convite mostra a cultura islâmica e tribal, onde as tribos do noivo e da noiva são fonte dos valores de prestígio, enquanto a religião islâmica é a fonte de satisfação maior, com ambas - tribo e religião - se sobrepujando a desejos e valores individuais. De uma perspectiva interna à cultura, Al-Ali identifica o lugar social desempoderado, determinado ao gênero feminino em uma sociedade patriarcal e antifeminista.

Nesses estudos sobre como a linguagem constitui os sistemas de atividades e relações sociais, os pesquisadores utilizam, como unidade de análise, um conceito de gênero que pressupõe a conexão entre atividade, relações sociais e texto para chegar ao discurso, à ideologia e à cultura. Os planos comunicativos atuantes no discurso e as relações entre texto e contexto (podem ser) são representados em uma adaptação de uma imagem da Linguística Sistêmico Funcional (LSF) (Fig. 1).

Na Fig. 1, cada círculo concêntrico, da fonologia ao discurso, engloba os círculos menores e assim subsequentemente (MARTIN 1992, p. 496). A linha mais espessa demarca o contexto que circunscreve os planos da fonologia, da gramática e da semântica, pertinentes ao sistema da língua. A imagem se presta 
a uma analogia visual do desenvolvimento cronológico dos estudos de gêneros discursivos em relação à estratificação dos planos comunicativos. A flecha ascendente indica o percurso cronológico dos estudos, nos séculos XX e XXI, em direção a um entendimento mais rico da conexão entre texto e contexto.

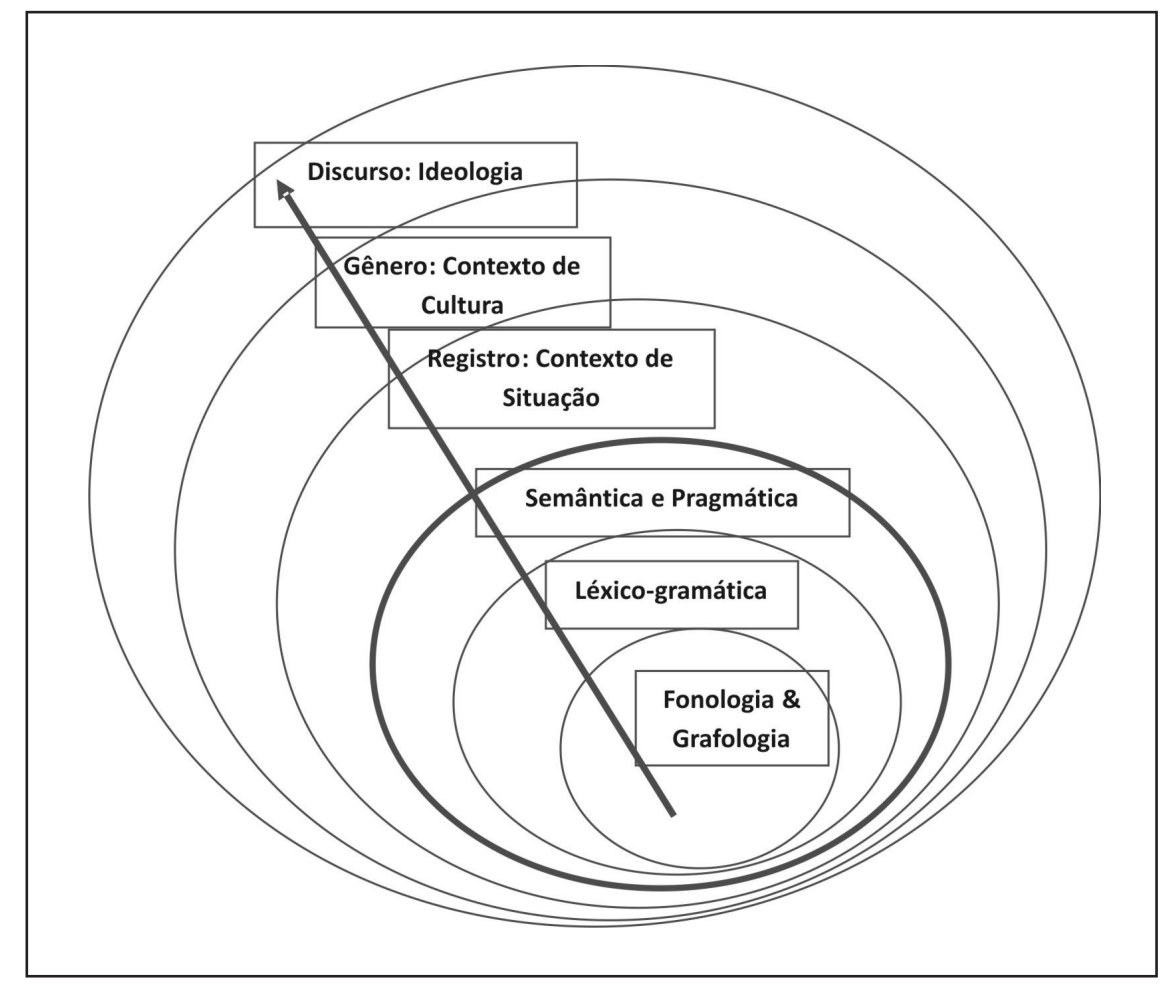

Fig. 1 Desenvolvimento cronológico dos estudos de gênero em relação à estratificação dos planos comunicativos (linguístico e contextual) (MOTTA-ROTH, 2008) 2,3

No nível intermediário, entre o sistema da língua e o discurso, há os contextos de uso da linguagem. O "Contexto de Cultura" diz respeito a todo o sistema social e é estruturado pelos vários gêneros que uma comunidade mobiliza na sua experiência de vida, enquanto que o "Contexto de Situação" diz respeito a cada situação específica que se realiza linguisticamente em registros específicos de cada gênero discursivo. "Contexto de Situação" é definido como o ambiente do texto, o conjunto de significados possíveis/prováveis (potencialmente disponíveis) em um dado momento da prática social (HALLIDAY, 1989). Registro é a "configuração dos recursos semânticos que o membro da cultura associa com o tipo de situação" (MARTIN, 1992, p.

3 Combinação e adaptação minhas de duas figuras de Martin (1992, p. 496) e Hendges (2005, p. 06). 498). Um artigo científico é um gênero que se realiza em diferentes registros realizados em diferentes revistas científicas de diferentes disciplinas. 
Podemos encontrar diferentes agrupamentos sociais ou "pequenas culturas" que perfazem o entorno social de cada sujeito. Tais grupos sociais se formam a partir de um critério ou um fim específico, de tal modo que um grupo social não pode ser fixado dentro de limites nacionais, étnicos ou econômicos, mas demanda critérios de relevância e interesse para seus membros para poder ser delimitado. Além disso, pela natureza fragmentada e múltipla da condição identitária contemporânea, cada sujeito pertence ao mesmo tempo a vários grupos sociais que lhe delimitam uma parcela de sua complexa identidade. Sobre isso, ver, por exemplo, Holliday (1999).
“Contexto de Cultura" é o conjunto articulado dos conceitos, dos valores, das crenças, do sistema de atividades e de gêneros tipicamente associados a um grupo social. ${ }^{3,4}$ Cada experiência individual de um dado contexto de cultura, em que um gênero é mobilizado, pode ser vista com um "Contexto de Situação" em que aquele gênero é atualizado em um registro, um tempo e um espaço social específicos. Gênero é uma conformação de significados recorrentes, organizada em estágios e orientada para o objetivo de realizar práticas sociais (MARTIN, 2002, p. 269). Essa conformação é específica da cultura (HALLIDAY, 1978, p. 145), portanto é uma unidade mais ampla do que o texto - "linguagem que é funcional", que realiza uma tarefa em algum contexto (HALLIDAY, 1985/1989, p. 5), "uma instância real de linguagem em uso" (FAIRCLOUGH, 2003, p.3) - e menos abrangente do que discurso - visões particulares formuladas na linguagem em uso (IDEM, IBIDEM). O estrato dos gêneros surge em conexão com sistemas de atividades e se localiza entre as situações concretas que vivenciamos e as ideologias que se estabelecem no mundo como um conjunto poderoso de ideias.

As atividades sociais podem ser definidas como ações por meio das quais as pessoas tentam alcançar determinados objetivos e que foram motivadas por outras ações do próprio sujeito ou de outros em um processo histórico dinâmico (KOZULIN, 1986, p. xlix).

As atividades socialmente reconhecidas são práticas sociais recorrentes mais ou menos estruturadas (como a cerimônia de casamento, a procura de emprego), com papeis sociais correspondentes (as relações de poder entre sogros e noivos, contratante e contratado) aos participantes de cada atividade. A linguagem é o sistema que dá existência material a atividades e papeis sociais. Como evento discursivo, o gênero articula a vida social em sistemas.

\subsection{Sistemas de gêneros}

A influência sócio-histórica associada ao círculo de Mikhail Bakhtin se faz sentir nos conceitos de sistema e conjunto de gêneros, descritos por Bazerman (2005) e Devitt (1991), na constatação sobre o modo como as práticas sociais se inter-relacionam pelo princípio da intertextualidade - como um gênero é produzido e transformado em um processo mediado pela relação deste com outros textos e outros gêneros (BERKENKOTTER, 2001, p. 326-27).

Em uma comunidade universitária, por exemplo, o sistema de gêneros é constituído pela interação dos participantes, mediada por textos (orais e escritos), em eventos sócio-historicamente situados, como o projeto de pesquisa, a sessão de orientação e a reunião departamental, a palestra, o artigo, livro e resenha, 
para o estabelecimento e o funcionamento dessa comunidade (DEVITT, 1991, p. 340). O sistema de gêneros é formado pela interação de todos os eventos discursivos que conformam essa comunidade ou que estão ligados a ela: as atividades no laboratório de pesquisa, no colegiado departamental, nos escritórios dos pesquisadores, no programa de pós-graduação, nas editoras que publicam os livros dos pesquisadores, nas livrarias que os vendem, nas bibliotecas que os compram, etc.

O conceito de sistema é importante porque nos ajuda a entender o modo como vários gêneros diacronicamente resultam de textos anteriores e influenciam textos futuros (IDEM, p. 353-354). Gêneros inter-relacionados poderão "seguir-se uns aos outros em arranjos específicos, porque as condições de sucesso das ações discursivas de cada gênero requerem vários estados de coisas para existir" (BAZERMAN, 1994, p. 98). Portanto a intervenção de cada gênero terá consequências para outros gêneros e atos de fala correspondentes que se seguirão na implementação de nossas intenções em sociedade e, ao mesmo tempo, resulta de todas as instâncias anteriores.

Os sistemas de gênero constituem a interação dos sujeitos e nas várias atividades em um dado grupo social e mobilizam a participação de todas as partes no processo de produção de conhecimento (BHATIA, 2004, p. 54). Por exemplo: diariamente, um laboratório de pesquisa de uma universidade se reestrutura pela participação dos vários atores sociais (mais e menos próximos do núcleo central da prática de produção do conhecimento): pesquisadores e alunos de pós-graduação que integram o laboratório de pesquisa, o chefe do departamento ao qual o laboratório está conectado, o editor de um periódico científico que publicará um artigo produzido pela equipe do laboratório, o editor-chefe da editora do livro do pesquisador-coordenador do laboratório, o colega ou aluno de pós-graduação que lerá o artigo e o citará em seu próprio texto ou lerá o livro e escreverá uma resenha sobre ele, o público-alvo para todos esses textos, etc. Além disso, podemos pensar no jornalista que lerá o artigo e escreverá uma notícia para popularizar essa pesquisa em um veículo de comunicação de massa.

A participação de todos esses atores sociais se dá em diferentes posições relativas a gêneros discursivos variados: o seminário de pesquisa, envolvendo pesquisadores e alunos de pós-graduação e iniciação científica; a sessão de orientação entre orientador e orientando(s); o artigo, o livro e a resenha, escritos por pesquisador(es) para pesquisadores; a notícia de PC, escrita por jornalista para o grande público, etc. Esses vários gêneros dialeticamente criam um sistema de gêneros e são criados por ele, como uma rede de práticas sociais inter-relacionadas em um mesmo contexto de cultura, com pontos mais e menos próximos dos centros de prestígio e poder. 


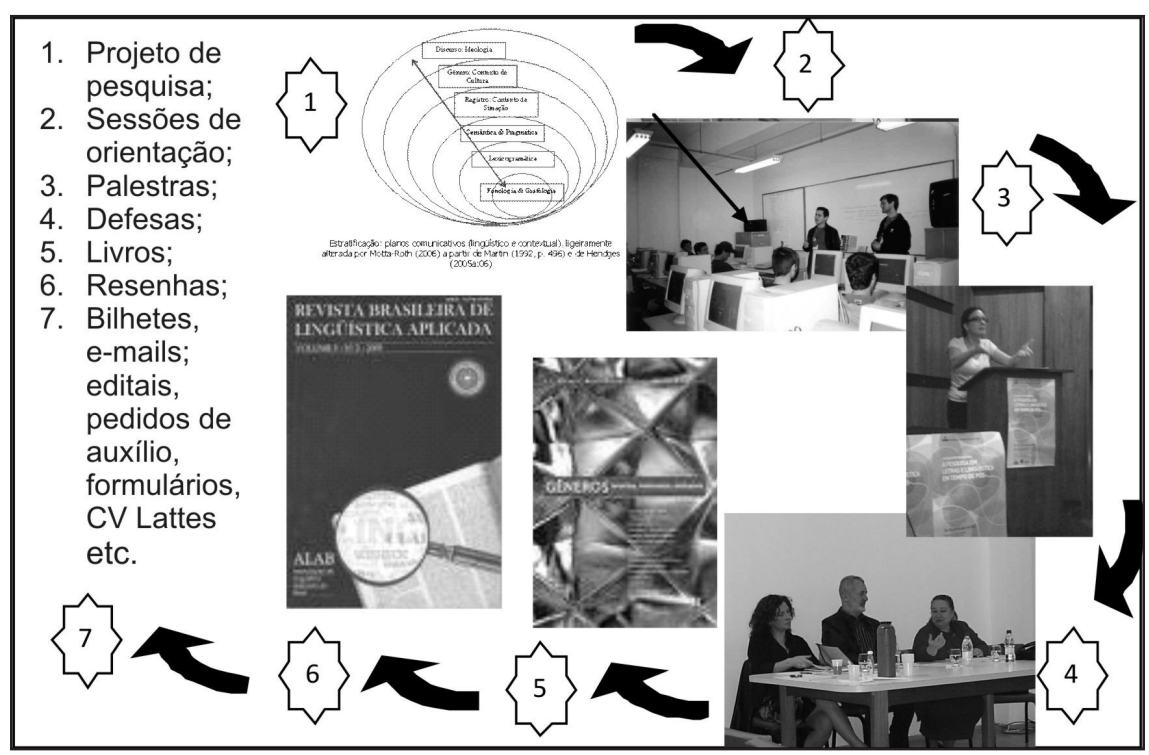

Fig. 2 Fluxo intertextual do sistema de gênero em um laboratório universitário de Linguística Aplicada (Motta-Roth, 2008; 2007a)

A Fig. 2 representa o sistema de gêneros do laboratório e pode ser descrita como:

um fluxo intertextual contínuo e não linear entre um projeto de pesquisa, o produto dessa pesquisa (na forma de livro, por exemplo) e a avaliação do mesmo (na forma de uma resenha do livro publicado). Assim, um projeto de pesquisa guardachuva é construído com base em outros textos lidos ou escritos anteriormente pelo grupo ou por outros autores. O projeto é então estudado e implementado, alterado, adaptado, e as idéias advindas daí são buriladas em: 1) sessões de orientação, 2) bancas de trabalhos de alunos, 3) palestras, e pode culminar na 4) publicação de um capítulo de livro que, por sua vez, poderá desencadear a 5) publicação de uma resenha crítica do livro, cuja leitura poderá influenciar novos textos, e assim por diante, num fluxo entre atividades institucionais eminentemente discursivas, orientadas para diferentes objetivos (MOTTA-ROTH, 2008, p. 364).

Gêneros, como enunciados relativamente estáveis, são atualizados em novas situações (registros) e seguem-se uns aos outros em contextos específicos, como condições discursivas necessárias para as práticas sociais se realizarem. Cada gênero terá consequências para os outros gêneros (e os atos de fala correspondentes) que se seguem no processo de concretização de nossos objetivos (BAZERMAN, 1994, p. 98).

O conceito de sistema de gêneros evidencia o papel de cada texto na manutenção da instituição científica. O conhecimento sobre como gêneros são intertextual e dialogicamente constituídos oferece possibilidades praxiológicas para que 
participantes entrem e saiam de gêneros letrados na pele de escritores, distribuidores e leitores de textos. Um pesquisador em formação pode se posicionar e produzir textos mais alinhados a seus objetivos se puder contar com análises sobre o modo como funciona o sistema de interações sociais, a intertextualidade e o dialogismo entre os gêneros que estruturam a comunidade em que se inscreve (MOTTA-ROTH, 2001).

Para alunos de pós-graduação e pesquisadores iniciantes, o conceito de sistema de gêneros (ou de "rede" para SWALES, 2004) é ainda mais importante porque esclarece como cada texto realiza sua parte nessa rede, como os textos juntos delimitam as atividades do grupo social. Também é importante diacronicamente, porque indica como os vários gêneros resultam de textos anteriores e influenciam os textos futuros (DEVITT, 1991, p. 353-354). Sistema de gêneros é a história de todos os eventos discursivos que se caracterizam em gêneros distintos, em ocorrências intertextuais, cada um como um ato em relação aos anteriores e posteriores, como instâncias de recontextualização, conforme argumento na próxima seção.

\section{Recontextualização, dialogismo e intertextualidade em notícias de popularização da ciência}

Faço aqui uma leitura particular de dois conceitos associados ao círculo de Bakhtin - dialogismo e intertextualidade - em combinação com um terceiro -recontextualização, da obra de Basil Bernstein $(1971 ; 1996)$ - para ilustrar minha discussão sobre sistemas de gênero no processo de midiatização ou popularização da ciência (PC): um processo discursivo de produção, distribuição e consumo de textos sobre novas pesquisas em campos especializados, cujos participantes-atores centrais são a ciência (o cientista), a mídia (o jornalista-mediador na impressa, na televisão, no rádio, etc.) e a sociedade (o público leitor não especialista) (MOTTA-ROTH, 2007b, p.2). Sua audiência-alvo é a sociedade mais ampla do que o grupo social estritamente formado por pesquisadores de uma determinada área de especialidade (MYERS, 2003, p. 265).

Tomo o exemplo de um gênero que chamo de "notícia de popularização científica", em que uma pesquisa (sua metodologia, seus resultados centrais e o significado desses resultados para a sociedade) é reportada em uma linguagem acessível a não especialistas. A notícia é uma combinação entre a manchete, o lide e o relato do evento principal - nesse caso, a realização de uma nova pesquisa, seu contexto, os eventos prévios e a relevância da pesquisa para a vida do leitor não especialista (MOREIRA; MOTTA-ROTH, 2008, p.4).

O processo de popularização ilustra o modo como uma prática social integra o processo mais amplo de produção e 
manutenção da ciência por meio das relações intertextuais e dialógicas entre os vários textos, gêneros e atores sociais que participam do mesmo sistema de gêneros.

\subsection{Recontextualização como coesão entre elos da cadeia histórica da comunicação verbal}

Na visão de Bernstein (1996, p.32), o texto posiciona sujeitos, é a forma de relação social tornada visível, material. Chama a transferência de textos de um "contexto primário" de produção do discurso para um "contexto secundário" de reprodução do discurso por meio de um contexto intermediário de "recontextualização". Para ele, a escola atua como campo recontextualizador (que faz a realocação) do discurso teórico-científico, fazendo um trabalho de adaptação deste para o consumo, em um processo de reprodução cultural da estrutura do sistema social, segundo a agenda institucional escolar. Na escola, assim como na sociedade em geral, há uma conexão estreita entre a construção (modelagem, shaping) da experiência, o sistema simbólico e a estrutura social, governada por relações de poder, portanto não só o capital econômico, mas também o capital cultural e simbólico estão sujeitos à apropriação, manipulação e exploração (BERNSTEIN, 1971, p. 172).

A escola, como outros contextos socializadores, se realiza na produção textual e privilegia certos significados (relações referenciais) relevantes em detrimento de outros. Os significados relevantes são privilegiados e privilegiantes: as relações referenciais privilegiadas têm prioridade (o que é consagrado como relevante hoje na sociedade e ocupa espaço na mídia, como, por exemplo, as pesquisas em medicina em comparação àquelas em linguística aplicada), e as privilegiantes conferem poder (o que consagra distinção e valor social à pessoa, objeto ou circunstância, como, por exemplo, a carreira médica consagra mais distinção e valor em comparação à docente) (BERNSTEIN, 1996, p. 30-31). Esses signifcados são, portanto, estruturados socialmente, determinados pela natureza das relações sociais e ativam escolhas gramaticais e lexicais específicas (BERNSTEIN, 1971, p.14).

Tomo a mídia como um contexto recontextualizador que mediatiza/populariza a ciência para a sociedade. Essa dinâmica envolve o deslocamento do discurso da ciência e do objeto do conhecimento científico, na sua materialidade textual, do seu contexto de produção primário para outro de consumo secundário (BERNSTEIN, 1996, p. 91). Os significados originalmente privilegiados e privilegiantes do artigo são selecionados, simplificados, condensados e elaborados em outro contexto de práticas interativas, por meio de paráfrase, substituições de termos espe- 
cializados por outros de uso cotidiano, analogias e comparações (MASSARANI; MOREIRA, 2005).

[Na] recontextualização, inicialmente há uma descontextualização: textos são selecionados em detrimento de outros e são deslocados para questões, práticas e relações sociais distintas. Simultaneamente, há um reposicionamento e uma refocalização. O texto é modificado por processos de simplificação, condensação e reelaboração, desenvolvidos em meio aos conflitos entre os diferentes interesses que estruturam o campo de recontextualização (LOPES, 2002, p.388).

O texto científico original é reposicionado, gerando outras posições de sujeito: se, no artigo científico, havia escritor-especialista/leitor-especialista, na notícia de popularização, há jornalista-especialista/leitor-não especialista. Refocalizam-se outros significados. Por exemplo, em artigos científicos, o foco é o autor e o que foi feito na pesquisa, portanto a primeira pessoa é usada ("We studied the basis for entrainment of circadian rhythms by food and light in mice"). Na midiatização da pesquisa, entretanto, o foco é o leitor, portanto é legítimo o jornalista usar a segunda pessoa para interpelar a audiência ("Your stomach may truly have a mind of its own."), captar sua atenção e estabelecer relação direta com ela logo de início para introduzir o tema (o da alimentação).

Muito embora esses deslocamentos sugiram uma ruptura, penso que recontextualização pressupõe referência cruzada entre textos. Na midiatização da ciência, um artigo científico publicado em uma revista acadêmica é lido por um jornalista que o seleciona, reelabora, refocaliza a partir dos interesses da instituição midiática de informatividade e de captação de audiência:

A finalidade do discurso de midiatização da ciência - que corresponde ao objetivo do ato de comunicação e que permite responder à pergunta "estamos aqui para dizer o quê?" - se constitui pelas visadas de informação e de captação. De acordo com Charaudeau (2008), a visada de informação do discurso de midiatização da ciência consiste em transmitir ao interlocutor conhecimentos ou eventos relacionados à ciência [fazer saber], enquanto a visada de captação corresponde a fazer o interlocutor sentir emoções agradáveis ou desagradáveis [suscitar interesse] a fim de captar a maior quantidade de leitores, no caso da mídia impressa (BECKER, 2010, p. 3-4)

Nas notícias de popularização já analisadas em trabalhos recentes, ${ }^{4,5}$ o diálogo e os contrapontos não podem ser vistos como rupturas entre o discurso da ciência e o da mídia jornalística, mas sim como um fluxo entre os discursos, gêneros e textos,

5 Ver MOTTA-ROTH e MARCUZZO (no prelo), MOTTA-ROTH e LOVATO (2009) e MOTTAROTH, GERHARDT e LOVATO (2008). numa relação dialética que estabelece apoio mútuo, mesmo na discordância. Essa relação imbricada se demonstra por índices linguísticos de dialogismo e intertextualidade como a interpe- 
lação explícita do leitor, o relato e a citação, ou as estratégias de pedagogização do discurso, como o aposto e a glosa.

\subsection{Dialogismo e intertextualidade}

A Mikhail Bakhtin é creditado o princípio do dialogismo da linguagem, segundo o qual todo ato humano é um texto que conversa com outros textos (1992, p. 332) precedentes aos quais responde e também se antecipa como horizonte de expectativa para respostas de outros textos que se seguirão. “Um ato humano é um texto em potencial, que pode ser entendido (como um ato humano e não como uma ação física) apenas no contexto dialógico de seu tempo" (IDEM, p. 334). Assim, toda compreensão é ativamente responsiva (IDEM, p. 67-9), pois (re)agimos à e por meio da linguagem.

As relações dialógicas ...são um fenômeno quase universal, que penetra toda a linguagem humana e todas as relações e manifestações da vida humana (Bakhtin, citado em BRAIT, 2009, p. 56).

Existe uma "relação de sentido entre enunciados" (BAKHTIN, 1992, p. 345), uma interação entre discursos, entre atos de fala, entre enunciados completos definidos como textos (IDEM, p. 330) e entre gêneros do discurso, entendidos como as formas dos enunciados, elaboradas por situações recorrentes (IDEM, p.305; 333):

Dois enunciados, separados um do outro no espaço e no tempo e que nada sabem um do outro, revelam-se em relação dialógica mediante uma confrontação do sentido (ainda que seja algo insignificante em comum no tema, no ponto de vista, etc.). (IDEM, p. 353-354).

Essa relação dialógica liga-se diretamente ao processo de intertextualidade, em que o enunciado produzido por outra pessoa, quando conscientemente percebido e distinguido em sua alteridade, é introduzido em nosso enunciado, em analogia com as relações existentes entre réplicas do diálogo (IDEM, p. 318):

Observam-se esses fatos acima de tudo nos casos em que o discurso do outro...é abertamente citado e nitidamente separado (entre aspas) e em que a alternância dos sujeitos falantes e de sua inter-relação dialógica repercute claramente (IDEM, IBIDEM).

A intertextualidade identifica o texto como enunciado (IDEM, p. 330). É a capacidade de um texto evocar outros textos existentes na cultura, como um elo na "cadeia de textos" (IDEM, p. 319, 332). Como "um mosaico de citações" (KRISTEVA, 1967 apud FIORIN, 2006, p.163), cada texto reflete os enunciados dos outros e, sobretudo, os elos anteriores (às vezes os próximos, mas também os distantes): 
...o objeto do discurso [do locutor] se torna, inevitavelmente, o ponto onde se encontram as opiniões de interlocutores imediatos (numa conversa...) ou então as visões do mundo, as tendências, as teorias, etc... (Bakhtin, 1992, p. 319). É dessa interação entre pontos de vista que surgem as "relações dialógicas intertextuais" (Idem, p. 331)

Nossos trabalhos recentes (com exemplares do gênero notícia de PC, publicados na mídia nacional e internacional $)^{5,6}$ sugerem a intertextualidade como princípio constitutivo de notícias de PC em português e inglês. "Há uma multiplicidade de vozes nesses textos que promovem o debate e possibilitam a explicação de novos conceitos e a avaliação do significado de novas pesquisas para a sociedade" (MOTTA-ROTH; MARCUZZO, no prelo, p.7).

Meu argumento aqui é que notícias de PC e o artigo científico não existem separadamente, mas integram um mesmo sistema de gêneros que produz e mantém a ciência ao recontextualizar seu objeto pelo princípio do dialogismo e pela capacidade intertextual da popularização. Evidência disso é a referência ao artigo científico que primeiramente relatou a nova pesquisa e que foi lido pelo jornalista para elaborar a notícia. Há aí uma sinalização do fluxo entre a ciência e sua popularização em diferentes graus de remoção (a que distância do contexto original o leitor é remetido) e de concretude (quão evidente e interativa é a sinalização).

Exemplo $1^{6,7}$

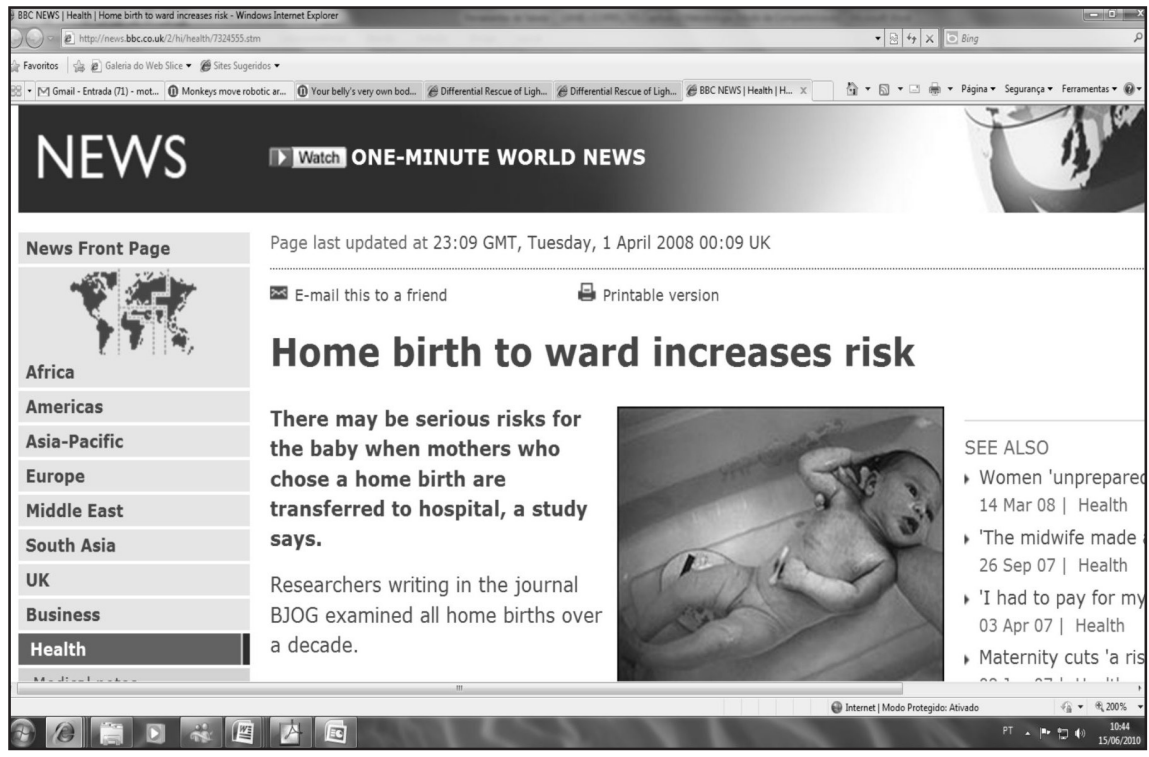

Idem nota 4

7 Home birth to ward increases risk. BBC News, 1 April 2008. Disponível em http://news. bbc.co.uk/2/hi/health/7324555.stm. Acesso em $14 / 06 / 2010$
Por exemplo, em um extremo de alto grau de remoção e baixo grau de concretude, pode haver uma simples menção do artigo científico em uma notícia, como ocorre consistentemente na revista eletrônica BBC News (Exemplo 1), que recontextualiza 
simplificada e remotamente a ciência em linguagem corriqueira, com raros termos técnicos e frequentes estratégias linguísticas de pedagogização, como aposto e glosa. Geralmente a referência à publicação do artigo aparece, sem qualquer hiperlink, logo no início da notícia (BJOG: An International Journal of Obstetrics and Gynaecology $y^{7,8}$ (no Exemplo 1), como apelo à autoridade, emprestando credibilidade às fontes do jornalista.

Muito frequentemente, há um alto grau de remoção por uma simples menção do artigo científico, harmonizada com linguagem corriqueira e aposto e glosa explicativos.

Exemplo 28,9

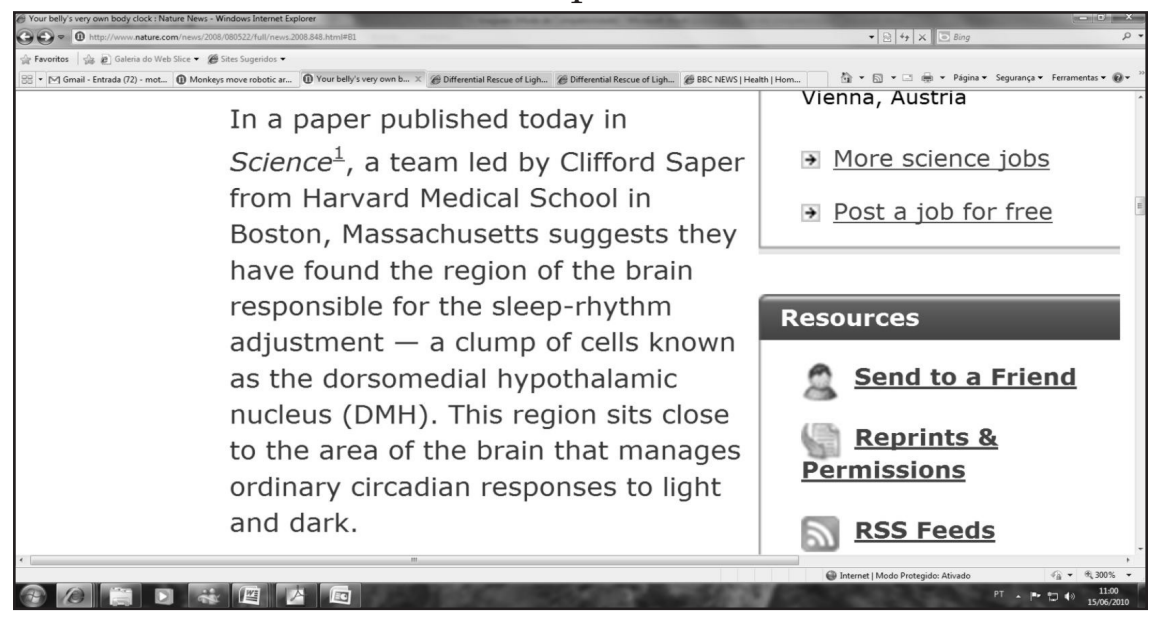

No entanto, há um médio grau de concretude em função da inserção de hiperlinks (localizados no texto ou perifericamente a ele, dentro da mesma tela) que dão visibilidade ao fluxo entre PC e produção primária da ciência ao direcionar o leitor para as referências bibliográficas na parte inferior da tela, ao final da notícia como no Exemplo 2. Ao clicar no índice sobrescrito em vermelho, ao lado do nome em itálico da Science (revista científica), o leitor é remetido às referências hiperlinkadas de outros endereços eletrônicos (fora da esfera da popularização), que lhe levarão ao resumo acadêmico do artigo original reportado na notícia (Exemplo 3). Aos poucos o leitor vai sendo recontextualizado da esfera midiática para a esfera científica. Uma nova tela, já na revista Science, possibilita a leitura do resumo acadêmico

8 Originalmente intitulado British Journal of Obstetrics and Gynaecology.

9 COURTLAND, R. Your belly's very own body clock. Nature News, 22 May 2008. Disponível em http:// www.nature.com / news/2008/080522/ $\mathrm{full} / \mathrm{news.2008.848.}$ html, Acesso em 14/06/2010. (abstract) do artigo (Exemplo 3). O grau de remoção diminui e de concretude da conexão aumenta, pois dessa tela do resumo, o leitor tem a opção de seguir navegando mais além. 
Exemplo 3,10

\begin{tabular}{|c|c|c|}
\hline Differentios Rescue of Light- and food-Entronst. & 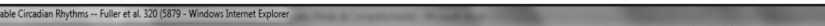 & \\
\hline 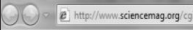 & 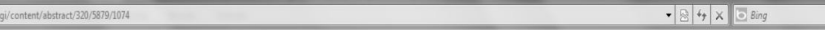 & \\
\hline 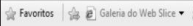 & A Stes Sugenidos $v$ & \\
\hline 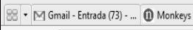 & 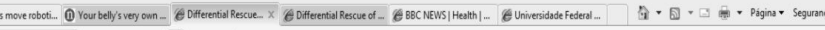 & Av Feramentas $=0$. \\
\hline$x$ Locoliarar citaģio & 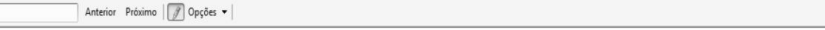 & \\
\hline Article Views & $\begin{array}{l}\text { Science } 23 \text { May 2008: } \\
\text { Vol. 320. no. } 5879 \text {, pp. } 1074 \text { - } 1077\end{array}$ & ADVERTK \\
\hline 'Abstract & DOl: $10.1126 /$ science. 1153277 & \\
\hline , Full Text (HTML) & REPORTS & \\
\hline , Full Text (PDF) & & \\
\hline 'Figures Only & Dirrerential Rescue or Lignt- and rood-entrainable Ulrcadian Rnytnims & \\
\hline $\begin{array}{l}\text { Supporting Online } \\
\text { Material }\end{array}$ & 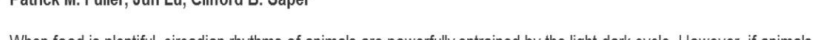 & \\
\hline 'Podcast Interview & have access to food only during their normal sleep cycle, they will shift most of their circadian rhythms to match the food & $\begin{array}{l}\text { Life Scie } \\
\text { Technology feat }\end{array}$ \\
\hline VERSION HISTORY & $\begin{array}{l}\text { of the clock gene Bmal1, which lack circadian rhythmicity. Injection of a viral vector containing the Bmal1 gene into the } \\
\text { suprachiasmatic nuclei of the hypothalamus restored light-entrainable, but not food-entrainable, circadian rhythms. In }\end{array}$ & \\
\hline Correction for this article & $\begin{array}{l}\text { contrast, restoration of the Bmal } 1 \text { gene only in the dorsomedial hypothalamic nucleus restored the ability of animals to } \\
\text { entrain to food but not to light. These results demonstrate that the dorsomedial hypothalamus contains a Bmal1-based }\end{array}$ & \\
\hline Article Tools & oscillator that can drive food entrainment of circadian rhythms. & \\
\hline , Save to My Folders & Department of Neurology, Division of Sleep Medicine, and Program in Neuroscience, Beth Israel Deaconess Medical & \\
\hline , Download Citation & Center, Harvard Medical School, Boston, MA 02215, USA. & \\
\hline $\begin{array}{l}\text { 'Alert Me When Article is } \\
\text { Cited }\end{array}$ & 'To whom correspondence should be addressed. E-mail: csaper@bidmc.harvard.edu & Discover 1 \\
\hline Post to CiteULike & 目 $\underline{\text { Read the Full Text }}$ & Therm \\
\hline & Ointenet|Modo Protegido: Ativado & A. $+100 \%$ \\
\hline
\end{tabular}

Hiperlinks, como Read the Full Text, marcado em azul ao final do resumo, exercem uma força centrípeta em direção à esfera de produção primária da ciência, ao conduzir o leitor ao texto integral do artigo (Exemplo 4).

${ }^{10}$ FULLER, P. M.; LU, J.; SAPER. C. B. Abstract de Differential rescue of light- and foodentrainable circadian rhythms. Science, v. 320. n. 5879 , p. $1074-1077,23$ May 2008. Disponível em http://www.sciencemag.org/cgi/content/ abstract/320/5879/1074. Acesso em 14/06/2010.

11 FULLER, P. M.; LU, J.; SAPER. C. B. Texto complete de Differential rescue of light- and foodentrainable circadian rhythms. Science, v. 320. n. 5879 , p. $1074-1077,23$ May 2008. Disponível em http://www.sciencemag.org/cgi/content/ full/320/5879/1074. Acesso em 14/06/2010.

\section{Exemplo $4^{10,11}$}

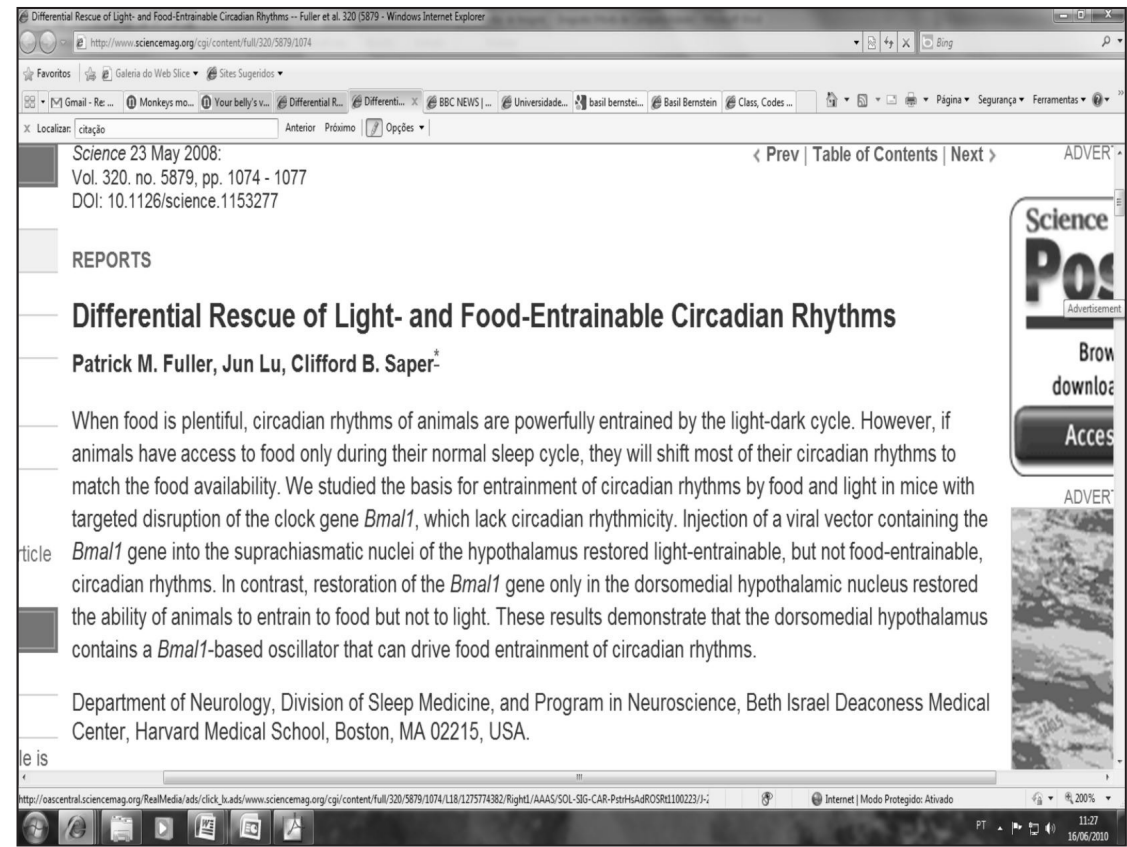


Esse roteiro de navegação, que leva o leitor, em uma recontextualização reversa, a cruzar a esfera midiática em direção à científica, parece ser recorrente no gênero notícia de $\mathrm{PC}$, tanto no âmbito internacional (como a Scientific American e a ABC Science) quanto nacional, conforme se vê na revista Ciência Hoje Online (Exemplo 5).

Exemplo $5^{11,12}$

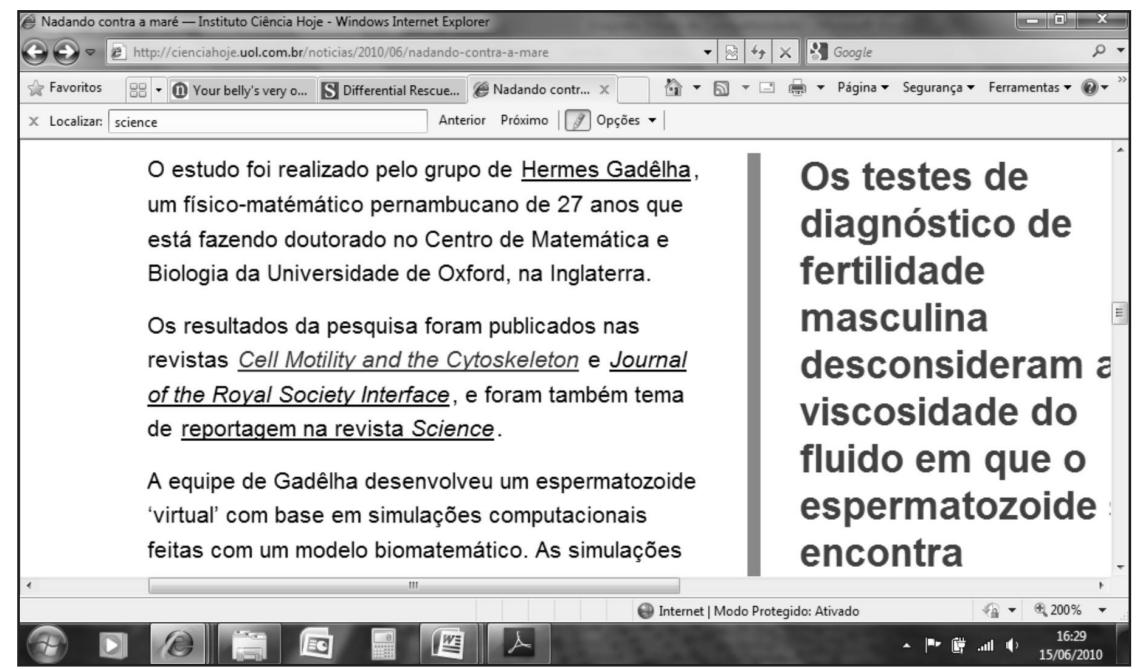

Uma segunda evidência linguística do princípio dialógico e da capacidade intertextual da recontextualização da ciência na mídia é a indicação de posições enunciativas intercaladas que opinam sobre a nova pesquisa reportada na notícia. Essas opiniões aparecem em citação (discurso direto) ou relato (discurso indireto) e podem ser de apoio (geralmente do próprio cientista que a desenvolveu) ou de discordância da pesquisa (geralmente de outro colega ou de uma instituição), como mostram os Exemplos 6 e 7, respectivamente:

Exemplo 6 ${ }^{12,13}$

${ }^{12}$ ANTUNES, D. Nadando contra a maré. Ciência Hoje Online, 14/06/2010. Disponível em http://cienciahoje.uol.com.br/noticias/2010/06/nadandocontra-a-mare. Acesso em 14/06/2010.

${ }^{13}$ Racial clues in bowel cancer find. BBC News, 31 March 2008. Disponível em http:// news.bbc.co.uk/2/hi/ health/7319251.stm. Acesso em 15/06/2010.

${ }^{14}$ Idem à nota 8.
Professor Malcolm Dunlop, at the Institute of Genetics and Molecular Medicine at the University of Edinburgh and who led the research, said: "This is the first time that a race-specific effect has been found for a genetic marker.

Exemplo $7^{13,14}$

But some researchers in the field have serious concerns about the work. "On the face of it, it's almost the final nail in saying DMH is the pacemaker, but under the surface there are people who strongly disagree," says neuroscientist Masashi Yanagisawa of University of Texas Southwestern Medical Center in Dallas, who was not involved in the work. 
O Exemplo 6 ilustra a inserção da voz do cientista, representando uma posição enunciativa que destaca a inovação de sua própria pesquisa (first time) e é legitimada por credenciais de cargo (Professor), instituição (Institute of Genetics and Molecular Medicine at the University of Edinburgh) e posição na equipe de pesquisa (led the research). O Exemplo 7 demonstra o contraponto, a inserção de vozes plenivalentes, ${ }^{14,15}$ de mesmo grau de potência, que oferecem contraponto. Nesse caso, a voz do colega pesquisador, também legitimada por credenciais (some researchers in the field; neuroscientist Masashi Yanagisawa of University of Texas Southwestern Medical Center in Dallas; who was not involved in the work), oferece, ao jornalista e ao leitor, sua crítica à pesquisa (serious concerns about the work; people who strongly disagree).

Nas notícias, ocorre a conversacionalização (FAIRCLOUGH, 1995, p.51), cadeias intertextuais como entrelaçamento de representações de vozes variadas em uma rede construída pelo jornalista para impor ordem e interpretação a elas (IDEM, p.77). Análise anterior (MOTTA-ROTH; MARCUZZO, no prelo) indica que vozes mais presentes são as do cientista e do colega, com muito menos ênfase para a voz de instituições governamentais e, com uma voz quase inaudível, o público. A respeito da inexistência da citação da voz do público nos textos da mídia, Fairclough (idem, p.49) observa que, em virtude do pressuposto de que jornalismo depende de fontes legitimadas (por credenciais, por exemplo), ao público é dado o direito a sua experiência, mas não a sua opinião. A tímida inserção da voz do público nas notícias de PC sugere que a visão otimista sobre a atual existência de um processo de democratização da ciência pela mídia é infundada ${ }^{15,16}$ e que ainda precisamos de mais compreensão sobre ciência para podermos opinar como voz individual.

\section{Considerações finais}

No presente trabalho, intertextualidade e dialogismo atuaram na recontextualização necessária e inerente ao funcionamento do discurso. Essa recontextualização de textos, pontos de vista, vozes, etc., só é possível pela existência de relações dialógicas entre gêneros que orbitam um mesmo sistema que produz e mantém a ciência.

No exame de seu histórico, qualquer problema científico (quer seja tratado de modo autônomo, quer faça parte de um

15 Aqui a conexão com o termo "polifonia" é uma possibilidade que tentarei aprofundar em outro trabalho.

${ }^{16}$ Conforme comunicação pessoal de Graciela Rabuske Hendges (UFSM) em 06/04/2010. conjunto de pesquisas sobre o problema em questão) enseja uma confrontação dialógica (de enunciados, de opiniões, de pontos de vista) entre os enunciados de cientistas que podem nada saber uns dos outros, e nada podiam saber uns dos outros. O problema comum provocou uma relação dialógica. (Ênfase minha) (BAKHTIN, 1992, p. 354) 
A recontextualização de um artigo científico que relata uma nova pesquisa em uma notícia de PC cria "um novo elo na cadeia histórica da comunicação verbal” (IDEM, p. 332) por meio de relações dialógicas e intertextuais. $\mathrm{O}$ fluxo discursivo entre ciência, mídia e sociedade não se manifesta de forma linear, como um contínuo, mas é pluridirecional: a ciência informa a mídia, esta informa o público, este, por sua vez, consome a midiatização e, por um processo de emergência (SAWYER, 2003) em que fenômenos macrossociais emergem das ações de vários indivíduos participativos, determina a agenda da mídia, assim como influencia os caminhos da ciência (MOTTA-ROTH, 2007b, p.3).

Oliveira (2005, p. 222) aponta que, assim como o artigo científico, a notícia de PC participa de um mesmo sistema semiótico no âmbito da ciência. Ambos estão inter-relacionados em complexas redes intertextuais de referência aos mesmos fatos científicos, mas com modos específicos de realização do significado em diferentes gêneros discursivos.

Nessa dinâmica de produção e manutenção da ciência, é evidente a importância do letramento científico popular - o desenvolvimento das habilidades para interagir com outras pessoas no papel de leitor e escritor em torno de conhecimentos especializados. A ciência como formação discursiva e ideológica, como esfera de atividade humana, depende de interlocutores que possam desafiá-la, alimentá-la, levá-la adiante e até derrubála para que novos paradigmas possam ser criados. É parte da cultura da sociedade e se beneficia do conhecimento popular sobre a natureza e a relação dos seres humanos com ela (MYERS, 2003, p. 271).

\begin{abstract}
:
In this paper I explore the process of science popularization from the vantage point of two concepts: genre system and recontextualization. I associate the socio-rhetorical and systemic-functional concepts of discourse genre with the socio-historical perspective (as credited to Mikhail Bakhtin and other authors along the same line) to define genre as a recurring discursive event in specific human activity spheres. I focus on the discursive process implemented by the midiatization of scientific research in science popularization publications divulged on the internet. The transposition of an ideational content from science (the new research, its methodology and results) in to the electronic media occurs in a recontextualization movement that relocates (parts of or whole) texts from one sphere of human activity to another, providing
\end{abstract}


visibility to the continuous flux between genres of the same system for science production and maintenance.

Keywords: Discourse genre. Sphere of human activity. Socio-rhetoric. Science popularization.

\section{Referências}

AL-ALI, M. N. Communicating messages of solidarity, promotion and pride in death announcements genre in Jordanian newspapers. Discourse \& Society, 2005, v. 16, n. 5, p. 5-31.

Religious affiliations and masculine power in Jordanian wedding invitation genre. Discourse \& Society, 2006, v.17, n. 6, p. 691-714.

BAKHTIN, M. Estética da criação verbal. São Paulo: Martins Fontes, 1952-1953/1992.

BAKHTIN, M. (VOLOCHINOV) Marxismo e filosofia da linguagem. São Paulo: Editora Hucitec, 1929/1995.

BAZERMAN, C. Systems of genre and the enactment of social intentions. In: Freedman, A.; Medway, P. (Eds.). Genre and the new rhetoric. London: Taylor \& Francis, 1994, p. 79-101.

Gêneros textuais, tipificação e interação. Tradução e organização de A. P. Dionísio; J. C. Hoffnagel. São Paulo: Cortez, 2005. BECKER, J. P. L. A restrição de visibilidade e os valores-notícia em textos de popularização da ciência da revista Veja. In: SELL, M.; GUIMARÃES, A. M. M. 2. Congresso Internacional Linguagem e Interação/UNISINOS, 2010, São Leopoldo, RS. Anais. São Leopoldo, RS: Casa Leiria, 2010, p. 1-12.

BERKENKOTTER, C. Genre systems at work: DSM-IV and rhetorical recontextualization in psychotherapy paperwork. Written Communication, v. 18, p.326-49, 2001.

BERNSTEIN, B. Class, codes and control, vol. 1, Theoretical studies towards a sociology of language. 2nd. edition. London: London Routledge \& Kegan Paul, 1971.

A estruturação do discurso pedagógico: classe, códigos e controle. Petrópolis: Vozes, 1996.

BHATIA, V. Worlds of written discourse: a genre-based view. London/New York: Continuum, 2004.

BRAIT, B. Problemas da poética de Dostoiévski e estudos da linguagem. In: . (Org.). Bakhtin, dialogismo e polifonia. São Paulo: Contexto, 2009, p. 45-72.

CHOULIARAKI, L.; FAIRCLOUGH, N. Discourse in late modernity: rethinking critical discourse analysis. Edinburgh: Edinburgh University Press, 1999. 
DEVITT, A. J. Intertextuality in tax accounting: generic, referential, and functional. In: Bazerman, C.; Paradis, J. (Eds.). Textual dynamics of the professions: historical and contemporary studies of writing in professional communities. Madison, WI: The University of Wisconsin Press, 1991, p. 336-357.

Analysing discourse: textual analysis for social research. London/New York, Routledge, 2003.

FAIRCLOUGH, N. Media discourse. London/New York/Sydney/ Auckland: Edward Arnold, 1995.

FIORIN, J. L. Interdiscursividade e intertextualidade. In: Brait, B. (Org.). Bakhtin: outros conceitos-chave. São Paulo: Contexto, 2006, p. 161-193.

GIANNONI, D. S. Worlds of gratitude: a contrastive study of acknowledgement texts in English and Italian research articles. Applied Linguistics, v. 23, n. 1, p.1-31, 2002.

HENDGES, G. R. A genre and register analysis of electronic research articles from a systemic functional perspective: new medium, new meanings. PHD project. Florianópolis: PPGI/ UFSC, 2005.

HALLIDAY, M. A. K. Language as social semiotic: the social interpretation of language and meaning. London: Edward Arnold, 1978. and text:

. Part A. In: M. A. K. Halliday \& R. Hasan. Language, context, aspects of language in a social-semiotic perspective. Oxford: Oxford University Press, 1985/1989, p.1-49.

HOLLIDAY, A. Small cultures. Applied Linguistics, v. 20, n. 2, p. 237-264, 1999.

HORGAN, J. O fim da ciência: uma discussão sobre os limites do conhecimento científico. São Paulo: Companhia das Letras, 1998. KOZULIN, A. Vygotsky in context. In: L. Vygotsky; A. Kozulin (trans.and rev.). Thought and language. Cambridge, Mass./ London, England: The MIT Press, 1986, p.xi-lvi.

LARSEN-FREEMAN, D; CAMERON, L. Complex systems and applied linguistics. Oxford: Oxford University Press, 2008.

LOPES, A. C. Os parâmetros curriculares nacionais para o ensino médio e a submissão ao mundo produtivo: o caso do conceito de contextualização. Educação e Sociedade, Campinas, vol. 23, n. 80, p. 386-400, setembro/2002.

MARTIN, J. English text: system and structure. Philadelphia/ Amsterdam: John Benjamins, 1992.

A universe of meaning - how many practices? In A. Johns

(Ed.) Genre in the classroom: multiple perspectives. Mahwah, NJ: Lawrence Erlbaum, 2002, p. 269-278. 
MASSARANI, L; MOREIRA, I.C. A retórica e a ciência: dos artigos originais à divulgação científica. Multiciência, n. 4, 2005.

MOREIRA, T. M.; MOTTA-ROTH, D. Popularização da ciência: uma visão panorâmica do "Diário de Santa Maria”. In: VIII Encontro do CELSUL-Círculo de Estudos Lingüísticos do Sul, 2008, Porto Alegre. Anais. Porto Alegre: UFRGS/CELSUL, 2008, p. 1-12. MOTTA-ROTH, D. Redação acadêmica: princípios básicos. Santa Maria: Laboratório de Pesquisa e Ensino de Leitura e Redação/ Imprensa Universitária, Universidade Federal de Santa Maria, 2001.

Diferentes tipos de texto ou diferentes gêneros? Conferência ministrada no II Curso de Atualização em Língua e Literatura: discutindo os diferentes tipos de texto, Cruz Alta, RS: UNICRUZ, 2007a.

Análise crítica de gêneros com foco em artigos de popularização da ciência. Projeto de Produtividade em Pesquisa PQ/ CNPq (n 301962/2007-3), 2007b.

Análise crítica de gêneros: contribuições para o ensino e a pesquisa de linguagem. D.E.L.T.A. - Documentação de Estudos em Linguística Teórica e Aplicada, São Paulo, v. 24, n. 2, p. 341383, 2008.

A popularização da ciência como prática social e discursiva. In: Encontro do núcleo de estudos avançados "Linguagem Cultura e Sociedade": GT LABLER, Módulo 5, 2009, Santa Maria. Anais. Santa Maria: LABLER/UFSM, no prelo.

; GERHARDT, L. B.; LOVATO, C. S. Organização retórica do gênero notícia de popularização da ciência: um estudo comparativo entre português e inglês. In: VIII Encontro do CELSUL-Círculo de Estudos Lingüísticos do Sul, 2008, Porto Alegre. Anais. Porto Alegre: UFRGS/CELSUL, 2008, p. 1-12.

.; LOVATO, C. dos S. Organização retórica do gênero notícia de popularização da ciência: um estudo comparativo entre português e inglês. Linguagem em (Dis)Curso, v. 9, n. 2, maio/ ago, 2009.

; MARCUZZO, P. Ciência na mídia: análise crítica de gênero de notícias de popularização científica. Revista Brasileira de Lingüística Aplicada, no prelo.

MYERS, G. Writing biology: texts in the social construction of scientific knowledge. Madison: University of Wisconsin Press, 1990.

Discourse studies of scientific popularization: questioning the boundaries. Discourse Studies, v. 5, n. 2, p. 265-279, 2003. OLIVEIRA, J. M. de. As vozes da ciência: a representação do discurso nos gêneros artigo acadêmico e de divulgação científica. 
Tese de Doutorado. Belo Horizonte, MG: POSLIN/Universidade Federal de Minas Gerais, 2005.

SAWYER, R. "Emergence and complexity: A new approach to social systems theory".Paper presented at the Annual Meeting of the American Sociological Association, Atlanta Hilton Hotel, Atlanta, GA Online, 2003. Disponível em http://www.allacademic.com/meta/p_mla_apa_research_citation/1/0/6/8/3/ p106832_index.html. Acessado em 15/06/2010.

SWALES, J. M. Other floors, other voices: a textography of a small university building. Mahwah, NJ: Lawrence Erlbaum, 1998.

Research genres: exploration and applications. Cambridge: Cambridge University Press, 2004. 